\title{
LIVROS DIDÁTICOS COMO TEXTOS DE MEMÓRIA: NOTAS SOBRE NARRATIVAS DA IMIGRAÇÃO ALEMÃ EM LIVROS DIDÁTICOS DE HISTÓRIA REGIONAIS
}

\author{
Rosiane Ribeiro Bechler ${ }^{1}$ \\ Cristiani Bereta da Silva²
}

\section{RESUMO}

Esse artigo analisa narrativas sobre imigração alemã "dadas a ler" em livros didáticos regionais sobre Santa Catarina, publicados entre 1920 e 1994. Os livros didáticos são aqui compreendidos como "textos de memória" e é por meio dessa chave de leitura que foram analisados. Tal como os antigos palimpsestos, são pensados como registros de memórias de diferentes temporalidades, que evidenciam esforços do presente na reelaboração do passado e indicam determinadas formas de interpretar que resistem ao tempo. Esse arco teórico-metodológico acompanha as reflexões apresentadas no livro Schulbuch und Erster Weltkrieg, publicado pelo Georg-Eckert-Institut für Schulbuchforschung. Apresentamos um breve resumo desse livro à guisa de introdução ao exercício proposto, qual seja: a partir da análise da escrita da História escolar, dotar de inteligibilidade o modo em que as narrativas sobre a vinda dos imigrantes alemães para Santa

${ }^{1}$ Universidade do Estado de Santa Catarina (Udesc), Florianópolis/SC, Brasil.

${ }_{2}^{2}$ Universidade do Estado de Santa Catarina (Udesc), Florianópolis/SC, Brasil. 
Catarina no século XIX foram elaboradas, alteradas, reiteradas no decorrer do século XX, indicando interpretações e memórias na composição de um traçado narrativo para a história desse Estado e de suas gentes. Uma das singularidades da questão diz respeito ao contingente de imigrantes europeus que se estabeleceram no Sul do país no decorrer do século XIX. Do traçado narrativo da historiografia didática sobre a vinda dos alemães para Santa Catarina destacamos dois eventos: (1) a vinda dos primeiros imigrantes alemães, ainda na década de 1820, e a fundação de São Pedro de Alcântara; (2) a fundação da atual cidade de Blumenau, em 1850. E, ainda, alguns traços da historiografia didática sobre as influências da cultura germânica na formação da gente catarinense. Como veremos, se São Pedro de Alcântara foi eleita para representar o passado, Blumenau busca no passado os contornos para sua afirmação no presente. Ambas atendem, contudo, à compreensão de que essa imigração se deu em prol do progresso e do desenvolvimento econômico e cultural de Santa Catarina.

Palavras-chave: textos de memória, livros didáticos regionais, imigração alemã.

\section{LIBROS DIDÁCTICOS COMO TEXTOS DE MEMORIA: NOTAS SOBRE NARRATIVAS DE LA INMIGRACIÓN ALEMANA EN LIBROS DIDÁCTICOS REGIONALES DE HISTORIA}

\section{RESUMEN}

Este artículo analiza narrativas sobre inmigración alemana presentes en libros didácticos regionales sobre Santa Catarina publicados entre 1920 y 1994. Los libros didácticos se comprenden aquí como "textos de memoria" y se analizan a partir de dicha clave de lectura. Así como los antiguos palimpsestos, se piensan como registros de memorias de distintas temporalidades, que ponen de relieve esfuerzos actuales de reelaborar el pasado e indican determinadas formas de interpretar que resisten al tiempo. Esa propuesta teórico-metodológico acompaña las reflexiones presentadas en el libro Schulbuch und Erster Weltkrieg, publicado por Georg-Eckert-Institut für Schulbuchforschung. Presentamos un breve resumen de este libro a modo de introducción al ejercicio propuesto, a saber: a partir del análisis de la escritura de la historia escolar, conferir inteligibilidad al modo en que las narrativas sobre la venida de los inmigrantes alemanes a Santa Catarina en el siglo XIX fueron elaboradas, alteradas y reiteradas en el curso del siglo XX, indicando interpretaciones y memorias en la composición de un trazado narrativo de la historia del Estado y de su gente. Una de las singularidades de la cuestión se refiere al contingente de inmigrantes europeos que se establecieron en el Sur del país al largo del siglo XIX. El trazado narrativo de la historiografía didáctica acerca de la llegada de los alemanes a Santa Catarina resaltar dos hechos: (1) la llegada de los primeros inmigrantes alemanes, incluso en la década de 1820, y la fundación de San Pedro de Alcántara; (2) la fundación de la actual ciudad de Blumenau, en 1850. Y, además, algunos rastros de la historiografía didáctica sobre las influencias de la cultura germánica en la formación de la gente catarinense. Como veremos, si San Pedro de Alcántara fue elegida para representar el pasado, Blumenau busca en el pasado los contornos para su afirmación en el presente. Ambas atienden, sin embargo, a la comprensión de que esa inmigración se dio en favor del progreso y del desarrollo económico y cultural de Santa Catarina.

Palabras clave: textos de memoria, libros didácticos regionales, inmigración alemana. 


\title{
TEXTBOOKS AS MEMORIAL TEXTS: NOTES ON GERMAN IMMIGRATION NARRATIVES IN REGIONAL HISTORY TEXTBOOKS
}

\begin{abstract}
This article analyzes narratives about German immigration found in regional textbooks about Santa Catarina, published between 1920 and 1994. These textbooks are here understood as "memorial texts", and it is from this perspective that they were analyzed. Such as ancient palimpsests, textbooks are understood as records of memories from different temporalities, which demonstrate the present efforts to rework the past and indicate certain forms of interpretation that resist time. Such a theoretical and methodological approach accompanies the reflections presented in the book Schulbuch und Erster Weltkrieg, published by the Georg-Eckert-Institut für Schulbuchforschung. A summary of the book was presented in the manner of an introduction to the proposed exercise, that is: from analyzing the writing of school History, to provide intelligibility to the narratives about the arrival of the German immigrants to Santa Catarina in the nineteenth century in order to understand how such narratives were elaborated, altered and reiterated throughout the twentieth century, indicating interpretations and memories in the composition of the history of this state and its people. One of the specificities of this question concerns the amount of European immigrants who settled in Southern Brazil throughout the 19th century. From the narrative outline of the didactic historiography on German immigration to Santa Catarina, we highlight two events: (1) the arrival of the first German immigrants in the decade of 1820 and the foundation of São Pedro de Alcântara; (2) the foundation of what is known today as the city of Blumenau, in 1850. Some traces of the didactic historiography on the influence of Germanic culture in the formation of the Catarinense people are also worth noting. As we shall see, if São Pedro de Alcântara was elected to represent the past, Blumenau seeks, in the past, the outlines of its affirmation in the present. Both attest, however, to the understanding that such an immigration occurred for the progress and the economic and cultural development of Santa Catarina.
\end{abstract}

Keywords: memorial texts, regional textbooks, german immigration.

\section{LES MANUELS SCOLAIRES COMME TEXTES DE MEMOIRE: REMARQUES SUR LES RECITS DE L'IMMIGRATION ALLEMANDE DANS LES MANUELS SCOLAIRES REGIONAUX D'HISTOIRE}

\section{RÉSUMÉ}

Cet article examine les récits de l'immigration allemande destinés à la lecture et contenus dans les manuels scolaires régionaux sur l'État de Santa Catarina publiés entre 1920 et 1994. Les manuels scolaires sont ici considérés comme des "textes de mémoire" et ont été analysés à travers de cette clé de lecture. Tout comme des anciens palimpsestes, ils sont conçus en tant qu'enregistrements de souvenirs appartenant à différentes temporalités qui mettent en évidence les efforts consentis aujourd'hui pour réélaborer le passé, et qu'indiquent certains modes d'interprétation qui résistent à l'épreuve du temps. Ce cadre théorico-méthodologique accompagne les réflexions présentées dans le livre Schulbuch und Erster Weltkrieg, publié par le Georg-Eckert-Institut für 
Schulbuchforschung et dont nous présentons un bref résumé à titre d'introduction à l'exercice proposé. À savoir: à partir de l'analyse de l'écriture de l'Histoire scolaire, doter d'intelligibilité la manière dont les récits sur l'arrivée d'immigrants allemands à Santa Catarina au XIXe siècle ont été préparés, modifiés et répétés au cours du XXe siècle, tout en soulignant les interprétations et les souvenirs dans la composition d'un récit traçant l'histoire de cet État et de son peuple. L'une des singularités de la question concerne le contingent d'immigrants européens qui se sont installés dans le sud du pays au cours du XIXe siècle. Du tracé narratif de l'historiographie didactique sur l'arrivée des Allemands à Santa Catarina, nous soulignons deux événements: (1) l'arrivée des premiers immigrants allemands, encore dans les années 1820, et la fondation de São Pedro de Alcântara; (2) la fondation de l'actuelle ville de Blumenau, datant de 1850. Et aussi quelques traces de l'historiographie didactique sur les influences de la culture germanique dans la formation du peuple de Santa Catarina. Comme nous le verrons, si São Pedro de Alcântara a été élu pour représenter le passé, Blumenau cherche dans le passé les contours de son affirmation au présent. Cependant, les deux assistent à la compréhension que cette immigration s'est passée en faveur du progrès et du développement économique et culturel de Santa Catarina.

Mots-clés: textes de mémoire, manuels scolaires régionaux, immigration allemande. 


\section{INTRODUÇÃO}

O livro didático é daqueles objetos que, dada a pluralidade de pesquisadores que sobre eles já se debruçaram³, podem parecer obsoleto para uns, mas para outros representam possibilidades ampliadas de compreensão da elaboração e circulação do conhecimento histórico na sociedade. Ademais é um objeto híbrido, constituído no tensionamento de forças advindas do campo pedagógico, das áreas específicas de conhecimento, do mercado editorial, das concepções políticas e das agendas e reclames sociais. Sua narrativa comporta assim diferentes vozes, em diálogo com os questionamentos próprios à sua temporalidade, e é, no limite, como toda escrita histórica, uma leitura autorizada pelos sujeitos no presente sobre os seus diferentes passados.

Foi esse olhar que as pesquisadoras do Georg-Eckert-Institut4 (GEI) Barbara Cristopher e Kerstin Schwedes lançaram sobre as narrativas em torno da Primeira Guerra Mundial publicadas em livros de diferentes países (Alemanha, Inglaterra, França, Finlândia, entre outros) e em variadas temporalidades, resultando na obra Schulbuch und Erster Weltkrieg (que em uma tradução livre seria Livro didático e Primeira Guerra Mundial), publicada em 2015 nas versões impressa e digital.5 Os objetivos centrais do trabalho desenvolvido foram entender o livro didático como "texto de memória", ou seja, como fonte para pesquisas sobre culturas da memória; e apresentar possibilidades do livro didático como fonte para ser explorada em sala de aula, problematizando a historicidade do conhecimento histórico. De acordo com as autoras:

${ }^{3}$ Sobre o amadurecimento do campo de pesquisas em torno dos livros didático ver: Munakata (2013).

4 O Georg-Eckert-Institut für International Schulbuchforschung está localizado na cidade de Braunschweig, na Alemanha, existindo sob essa denominação desde 1975. Além de desenvolver projetos próprios de pesquisa, o instituto incentiva, por meio de bolsas, a visita e permanência de pesquisadores em diferentes níveis de formação em suas dependências. Mais informações a respeito no site: http://www.gei.de.

5 A versão digital da obra pode ser acessada através do link: http://www.gei.de/publikationen/ eckert-expertise/ee-einzelband/news/detail/News/barbara-christophe-kerstin-schwedes-hgschulbuch-und-erster-weltkrieg-1.html. Acesso em: 10 fev. 2018. 
Mais uma vez, culturas da memória, como desejamos mostrar com nosso livro, são reunidas em livros didáticos em lentes convergentes. Livros didáticos refletem como quase nenhuma outra mídia, de que maneira acontecimentos históricos no decorrer de dezenas ou centenas de anos são lembrados em uma Nação (CHRISTOPHE; SCHWEDES; 2015, p. 9). ${ }^{6}$

E ainda,

Por outro lado, desejamos mostrar para professores e professoras como eles podem explorar representações de livros didáticos de diferentes tempos e de diferentes lugares, para partilhar com os estudantes nas aulas de História um conhecimento reflexivo sobre a mobilidade [Santdortgebundenheit] das culturas da memória (CHRISTOPHE; SCHWEDES, 2015, p. 10).7

A interpretação desenvolvida pelas autoras é fundamentada nas teorias da memória, das quais Maurice Halbwachs foi o precursor e cujo pensamento foi sintetizado da seguinte maneira:

Primeiro, assim escreveu Halbwachs já nos anos 20 do século $\mathrm{XX}$, as memórias nunca reproduzem simplesmente o passado. Lembrar é sempre um processo ativo, que delineia um quadro do passado, o organiza em alguma medida, na qual decide o que é e o que não é importante, em qual contexto o acontecimento será colocado e qual significado lhe será atribuído. Segundo, ainda de acordo com Halbwachs, o quadro que construímos do passado carrega sempre a assinatura do presente no qual vivemos. Dito e pontuado de outra forma: nós adaptamos o que nos é importante do passado às necessidades que temos hoje. E finalmente terceiro, para todas as decisões de escolha que nós encontramos, na acentuação que fazemos,

6 Tradução livre de Rosiane Bechler. No original em alemão: "Erinnerungskulturen wiederum, so möchten wir mut unserem Buch zeigen, werden in Schulbücher wie in einem Brennglas gebündelt. Schulbücher spiegeln wie kaum ein anderes Medium, auf welche Weise historische Ereignisse in einer Nation über Jahrzehnte oder Jahrhunderte hinweg erinnert werden" (CHRISTOPHE; SCHWEDES, 2015, p. 9).

7 Tradução livre de Rosiane Bechler. No original em alemão: "Zum anderem wollen wir LehrerInnen zeigen, wie sie Schulbuchdarstellungen aus unterschiedlichen Zeiten und von unterschiedichen Orten nutzen können um SchüllerInnen in Geschichtesunterricht ein reflexives Wissen über die Standortgebundenheit von Erinnerungskulturen zu vermieteln" (CHRISTOPHE; SCHWEDES, 2015, p. 10). 
acompanham regras sociais da memória (CRISTOPHER; SCHWEDES, 2015, p. 18). ${ }^{8}$

Por essa perspectiva as autoras compreendem que a narrativa do livro didático e a interpretação que dela fazemos estão impregnadas dos sentidos de memória, constituindo um "ponto cego" (blinden Fleck) na leitura do presente sobre o passado. Esse "ponto cego" seriam interpretações partilhadas em sociedade que, em certa medida, orientam a aprendizagem histórica também em sala de aula. Nessa perspectiva, "reconhecer esse ponto cego coloca-se como um desafio particular aos que ensinam e aos que aprendem"9 (CHRISTOPHE; SCHWEDES, 2015, p. 10), se mobilizados pelo desejo de decodificar a compreensão que cada presente incita sobre seu passado.

Ao dirigir o olhar para "o quê" e "como" se narra sobre a Primeira Guerra em diferentes países e em diferentes tempos, Christophe e Schwedes (2015) valorizam a desconstrução do discurso instituído e a exposição da multiperspectiva para a compreensão dos diferentes sentidos elaborados para um fato histórico singular e de destaque na história da Europa. Além disso, atentam também para a forma como os próprios livros didáticos "incentivam os leitores a desconstruir as narrativas didáticas e reconhecê-las como um dentre outras formas de narrativas imagináveis"10 (CHRISTOPHE; SCHWEDES, 2015, p. 11)

\footnotetext{
8 Tradução livre de Rosiane Bechler. No original em alemão: "Erstens, so schrieb Halbwachs schon in den 2oer Jahren des 20. Jahrhundert, bildet Erinnern das Vergangene niemals einfach nur ab. Erinnern ist immer ein aktiver Vorgang. Es entwirft ein Bild von der Vergangenheit, es richtet sie gewissermaßen zu, indem es darüber entscheidet, was wichtig und was nicht, in welchen Kontext ein Ereignis gestellt wird und welche Bedeutung ihm zugeschrieben wird. Zweitens, so Halbwachs weiter, trägt das Bild, das wir von der Vergangenheit schaffen, immer die Signatur der Gegenwart, in der wir leben. Anders und pointiert ausgedrückt: Wir passen das, was uns aus dem Gersten wichtig ist, an die Bedürfnisse an, die wie heute haben. Und drittens schielißlich, bei all den Auswahlentscheidungen, die wir treffen, bei den Akzentuierungen, die wir vornehmen, folgen wir sozialen Regeln des Errinerns" (CHRISTOPHE; SCHWEDES, 2015, p. 18).

9 Tradução livre de Rosiane Bechler. No original em alemão: "Diesen 'blinden Fleck' wahrzunehmen, stellt eine besondere Herausforderung na Lehrende und Lernende dar" (CHRISTOPHE; SCHWEDES, 2015, p. 10).

${ }^{10}$ Tradução livre de Rosiane Bechler. No original em alemão: "inwieweit sie selber die Leserinnen dazu anregen, Schulbuch-Narrative zu dekonstruieren und als eine von mehreren denkbaren Erzählweisen zu erkennen" (CHRISTOPHE; SCHWEDES, 2015, p. 11).
} 
orientadas pelo desejo de "desenvolver ferramentas que possam servir para, em sala de aula, ler e entender as narrativas do livro didático com um olhar crítico"11 (CHRISTOPHE; SCHWEDES, 2015, p. 11-12).

Na escrita da obra Schulbuch und Erster Weltkrieg, chama atenção o cuidado e a preocupação das autoras de que o conhecimento ali sintetizado, advindo de um projeto de pesquisa financiado pelo GEI, seja acessível e significativo para os professores que atuam em sala de aula. Para tanto os princípios teóricos e metodológicos que fundamentam o trabalho estão expostos de maneira clara, consistente e objetiva, e os dois últimos dos cinco capítulos tratam de exemplos práticos para o trabalho com essa perspectiva em sala de aula. Além disso, mesmo na exposição das bases teóricas, as fontes de análise são chamadas a compor o texto, em um claro esforço de possibilitar aos leitores o confrontamento e a elaboração de sentidos. Assim, o desafio a que se propõe o estudo - que aqui resenhamos como introdução ao nosso artigo - pressupõe um comprometimento coletivo e a parceria entre pesquisadores e docentes universitários, discentes em formação na graduação e os já licenciados que atuam em sala de aula, na Educação Básica. Demanda também uma guinada na maneira de olhar o livro didático, e de ler e problematizar suas narrativas históricas com um olhar histórico, que considere as particularidades da historiografia didática.

As autoras pontuam, ainda, como as pesquisas sobre livro didático na Europa tiveram por um tempo caráter "avaliador", assumindo para si a tarefa de fazer "juízo de valor" das narrativas históricas divulgadas por esse suporte. E problematizam o reduzido espaço ocupado por pesquisas que lançam um "olhar desinteressado sobre os livros”. Ou seja, pesquisas que não se ancorem em identificar os problemas nesses suportes, mas sim na busca da verdade interna do texto, na compreensão "do por que e ante qual plano de fundo das visões de mundo autores e autoras escrevem sobre determinada coisa exatamente com

\footnotetext{
${ }^{11}$ Tradução livre de Rosiane Bechler. No original em alemão: "Handwerkzeug entwickeln, das im Unterricht dazu dienen kann, Schulbucherzählungen mit kritischem Blick zu lesen und zu verstehen" (CHRISTOPHE; SCHWEDES, 2015, p. 11-12).
} 
essas palavras e silenciam outras" (CHRISTOPHE; SCHWEDES, 2015, p. 19). ${ }^{12}$

A potencialidade desse "olhar desinteressado" estaria em reconhecer então, no "texto de memória", que a linguagem que o constitui não apenas traduz no presente seu passado, mas confere sentido às palavras que imprime, da maneira com que as organiza - seus verbos, seus objetos, seus sujeitos. Assim, "quem analisa livros didáticos, o faz entretanto, para buscar indicações sobre os regimes de verdades válidos em uma sociedade, ou seja, o que definia os discursos então válidos como verdadeiros" (CHRISTOPHE; SCHWEDES, 2015, p. 20). Mas, para além disso, busca também identificar as diferentes vozes conjugadas na composição da narrativa didática, de natureza híbrida, “dando a ver” também o caráter eminentemente político da memória, tal qual os estudos mais recentes do campo têm demonstrado ${ }^{13}$. Além de sua natureza híbrida, o livro didático deve ser considerado também um objeto de fronteira, situado entre diferentes sistemas de partilhas da sociedade, configurando-se assim como um "nó" entre discursos sociais plurais.

Em termos metodológicos, Christophe e Schwedes se esforçaram para identificar: (1) "o que é contado e o que é deixado de lado"14, ou seja, quais as operações de escolha efetivadas em livros didáticos, no caso ingleses, de diferentes temporalidades. Esses livros, analisados de maneira diacrônica possibilitaram identificar, por exemplo, conteúdos que foram apresentados em livros antigos, mas que nos livros atuais foram deixados de lado; e quando analisados de maneira sincrônica possibilitam entrever as particularidades das narrativas nacionais de países distintos, como Inglaterra e Alemanha; (2) a partir das narrativas didáticas selecionadas, as autoras perguntaram "como"

12 Tradução livre de Rosiane Bechler. No original em alemão: "gewiessermaßen interesselosen Blick auf Schulbücher, der nicht gleich einen (vermeintlich objektiven) Maßtab anlegt und nach Fehlern sucht, sondern vielmehr danach trachtet, die innere Wahrheit einer Textes freizulegen und verstehend nachvollzuzihen, warun und vor dem Hintergrund welcher Weltsichten AutorInnen über das eine in genau diesen Worten screiben und vom anderen schweigen" (CHRISTOPHE; SCHWEDES, 2015, p. 19).

13 Entre os teóricos que discutem as relações entre memória e história, ver Paul Ricoeur (2007).

14 Tradução livre de Rosiane Bechler. No original em alemão: "was erzählt und was ausgelassen wird" (CHRISTOPHE; SCHWEDES, 2015, p. 30). 
determinado fato é narrado, partindo do pressuposto da análise do discurso de que "tudo que é dito pode ser dito de outra forma"15. Assim, foram analisadas a escolha das palavras, o grau de intencionalidade, as estruturas sintáticas (passivas e ativas), as implicações e pressuposições, para se compreender os sentidos que determinada forma de escrever impregnam nas narrativas didáticas; e por fim (3), analisou-se "o que é contado", empreendendo mais uma vez um quadro de análise diacrônica para mapear mudanças e continuidades nas narrativas didáticas (CHRISTOPHE; SCHWEDES, 2015, p. 30-32).

Entre os ajustes de foco que as autoras fazem sobre seus objetos de estudo, cabe destacar a análise de como as diferentes narrativas dão sentido à eclosão da guerra e à responsabilidade e participação de países como Alemanha, Inglaterra e França nesta. Outra análise instigante é sobre o "Atentado de Sarajevo", seus personagens e sua contextualização, ou ausência desta, nos diferentes livros investigados. Além disso problematizam, principalmente a partir das narrativas atuais, em que medida a globalização tem tornado as compreensões históricas em diferentes países mais ou menos semelhantes. Em suma, na parte teórica e metodológica da obra Schulbuch und Erster Weltkrieg, que nos interessa de maneira particular para composição deste artigo, Christophe e Schwedes buscaram enfatizar o uso heurístico de livros didáticos como fonte para a reconstrução de processos de negociação de culturas da memória. E é nessa perspectiva que também lançamos um "olhar desinteressado" sobre quatro livros de história sobre Santa Catarina, em um exercício metodológico de comparação entre narrativas sobre eventos particulares à história desse Estado, elaboradas em temporalidades distintas.

Importa registrar que as questões tratadas nesse artigo se relacionam a pesquisas mais abrangentes desenvolvidas pelas autoras sobre história regional, livros didáticos e conhecimento histórico escolar ${ }^{16}$. Em se tratando

\footnotetext{
15 Tradução livre de Rosiane Bechler. No original em alemão: “dass alles, was gesagt wird, auch anders gesagt werden könnte" (CHRISTOPHE; SCHWEDES, 2015, p. 31).

${ }^{16}$ No caso de Rosiane Bechler, trata-se de suas pesquisas desenvolvidas no âmbito do mestrado (BECHLER, 2014) e do doutorado (BECHLER, 2018), com financiamento da Capes. Já Cristiani
} 
especificamente da análise sobre as narrativas sobre a imigração alemã nos livros didáticos, a discussão constitui-se em recorte da pesquisa que resultou na tese de doutorado Entre traçar histórias e tecer identidades: narrativas da historiografia didática regional sobre Santa Catarina (BECHLER, 2018). Nesse trabalho analisou-se a historiografia escolar sobre Santa Catarina a partir de dez livros didáticos regionais, publicados entre 1920 e 2016. Estas obras foram consideradas em suas dimensões materiais e simbólicas, e no atravessamento das culturas históricas e escolares nas quais foram publicadas. Elaborou-se um arco teórico-metodológico que as organizou em tempos de escrita (sedimentação, invenção, consolidação, transição e reformulação), a partir da apropriação do instrumento heurístico do "código disciplinar" proposto por Raimundo Cuesta Fernandez (2002). No esforço de compreender os sentidos engendrados na longa duração pelas narrativas históricas voltadas à escola, mobilizou-se a compreensão dos livros didáticos como "textos de memória" (CHRISTOPHER; SCHWEDES, 2015), tal qual a proposta apresentada também neste artigo. Do cruzamento dessa perspectiva da memória com o código disciplinar elaborou-se a ideia de que, a escrita da História escolar constitui-se e orienta-se por traçados narrativos que atravessam diferentes tempos.

Antes mesmo da obra Schulbuch und Erster Weltkrieg, Barbara Christophe (2013), ao problematizar "o que exatamente confere valor ao livro didático como texto de memória”, argumentava:

Acredito que seja seu caráter híbrido [...]. Por um lado, eles [os livros didáticos] transportam algo como a representação oficial ou canônica da história nacional. Praticamente em todos os lugares do mundo as elites governamentais utilizam livros didáticos para propagar uma representação tão coerente quanto possível sobre o passado e com isso garantir influência sobre a formação de uma versão privilegiada da identidade nacional. Por outro lado, os livros didáticos são também ponto de confluência em uma rede de discursos sobre o passado em parte controversos ou contrários [...]. Portanto, via de regra, os livros

Bereta da Silva, de suas pesquisas realizadas no âmbito dos Programas de Pós-Graduação em História e em Educação, da Universidade do Estado de Santa Catarina (Udesc), com financiamento do CNPq, e que vem sendo divulgadas por meio de artigos, capítulos e livros. 
didáticos também refletem de uma ou de outra forma controvérsias sociais sobre temas sensíveis da memória. Não raramente, tudo isso confere às narrativas didáticas tensões e ambivalências.

A dupla tarefa das análises dos livros didáticos orientadas pela cultura da memória consiste, portanto, a partir do meu ponto de vista, em tornar visível no texto [didático] tanto os discursos hegemônicos como também as marcas de debates sociais controversos (CHRISTOPHE, 2013, p. 145-146). ${ }^{17}$

Pensar o livro didático como "texto de memória" também dialoga com as reflexões propostas pelo historiador Habbo Knoch (2001), que mobilizou o referido conceito em seu trabalho sobre as representações da Segunda Guerra Mundial em imagens veiculadas na Alemanha. Para esse autor, "textos de memória” (Erinnerungstext) podem ser compreendidos como Palimpsestos (Palimpseste), ou seja, papéis em que se apagam os escritos no intuito de reaproveitá-los para novas escritas. Mas, como bem sabemos, a borracha não consegue subtrair as marcas profundas do papel, que se perpetuam como sombras que obscurecem e/ou orientam sentidos aos novos textos sobre ele inscritos.

\footnotetext{
${ }^{17}$ Tradução livre de Rosiane Bechler. No original, em alemão: “[...] was genau eigentlich den Wert von Schulbüchern als Erinnerungstexten ausmacht. Ich glaube, es ist ihr hybrider Charakter. [...] Einerseits transportieren sie so etwas wie das offizielle oder kanonisierte Bild der nationale Gechichte. Nahezu überall auf der Welt nutzen staatliche Eliten Schulbücher, um ein möglichst kohärentes Bild der Vergangenheit zu propagieren und damit Einfluss auf die Herausbildung einer privilegiertern Version nationaler Identität zu nehmen. Anderseits sind Schulbücher aber auch Knotenpunkte in einem Netz von z. T. sehr wiedersprüchlichen oder gar gegensätzlichen Diskurse über die Vergangenheit. [...] In der Regel reflektiren Schulbücher deshalb auf die ein oder andere Weise auch gesellschaftliche Kontroversen über sensible Themen der Erinnerung. All das trägt nicht selten Spannungen und Ambivalenzen in Schulbuchnarrativen hinein. Die doppelt Aufgabe einer erinnerungskulturell orientierten Schulbuchanalyse besteht deshalb, aus meiner Sicht darin, sowohl hegemoniale Diskurse als auch Spuren kontroverser gesellschaftlicher Debatten in den Text sichtbar zu machen" (CHRISTOPHE, 2013, p. 145-146).
} 


\section{PALIMPSESTOS SOBRE A IMIGRAÇÃO ALEMÃ EM SANTA CATARINA}

O exercício aqui proposto centra-se no esforço de identificar "o que" se narra e "como" se narra no decorrer do século XX sobre a vinda de imigrantes alemães para Santa Catarina (século XIX) e os sentidos que lhes foram atribuídos sobre a formação das gentes e culturas catarinenses. Para tal empreendimento elegemos as seguintes obras ${ }^{18}$ :

1. Pequena História de Santa Catarina (BOITEUX, 1920), considerado o primeiro livro didático sobre a história do Estado (SILVA, 2014a), destinado aos quartos anos dos Grupos Escolares e à formação nas Escolas Normais;

2. Santa Catarina História da Gente (PIAZZA; HÜBNER, 1987), livro didático elaborado para uso no então nomeado Segundo Grau (atual Ensino Médio), escolhido dada sua presença longeva e tradicional na bibliografia sobre o Estado, sendo referência de todos os demais livros analisados e referenciando ele mesmo obras de Lucas Boiteux;

3. Os Catarinas - Terra e Gente (PIAZZA; LOMBARDI; LEITE, 1994), obra contemporânea ao livro anterior e também de autoria de Piazza, cuja narrativa traz elementos que, em uma análise sincrônica, permitem problematizar recortes privilegiados por diferentes obras de uma mesma temporalidade histórica.

4. Santa Catarina, Estudos Sociais - Coleção Meu Estado (QUEVEDO;

\footnotetext{
${ }^{18}$ Como já informado, essas obras foram eleitas dentre um conjunto mais amplo de livros de história regional sobre Santa Catarina, publicados entre 1920 e 2016. O livro de Lucas Boiteux (1920) faz parte desse recorte pelo seu papel inaugural da historiografia didática sobre Santa Catarina. As obras que Piazza escreveu em coautoria com outros professores e pesquisadores também ocupam um lugar de relevância, dado o lugar desse autor entre os intelectuais catarinenses. E, por fim, agregamos a essa análise o livro escrito por Quevedo et al. dada a sua contemporaneidade com a segunda obra de Piazza (1994), possibilitando assim um movimento de análise sincrônica.
} 
ORDOÑES; SALES, 1994), obra publicada no contexto de junção das disciplinas História e Geografia no currículo do Ensino Fundamental, e já apresentando recursos gráficos e pedagógicos que dialogavam com as discussões educacionais em pauta à época.

A análise desses livros como "textos de memória", implica reconhecer que as narrativas históricas escolares ali divulgadas - ainda que reescritas em temporalidades distintas - carregam consigo sentidos profundos estabelecidos e legitimados por culturas de memória que se perpetuam e se reinventam no tempo, subsidiando compreensões do presente sobre seus passados. A partir desse entendimento retomamos a pergunta: o que se conta e como se conta sobre a vinda de imigrantes alemães para Santa Catarina em livros didáticos de História Regional? E de que maneira as narrativas didáticas elaboram sentido para a contribuição desses povos para a formação da gente catarinense?

Sob essa perspectiva pretendemos dar a ver essas marcas da escrita que se perpetuam no tempo delineando padrões de interpretação para a História de Santa Catarina no tocante à composição de sua gente. Uma das singularidades da questão diz respeito ao contingente de imigrantes vindos da Alemanha, da Itália e de outros países europeus no decorrer do século XIX. Por isso, fizemos um ajuste de escalas na leitura das narrativas didáticas que privilegia dois fatos históricos em particular: (1) a vinda dos primeiros imigrantes alemães, ainda na década de 1820, e a fundação de São Pedro de Alcântara, hoje cidade considerada a "primeira colônia de alemães" em Santa Catarina; (2) a fundação da atual cidade de Blumenau, datada de 1850, em um período já com outras conformações políticas e demandas sociais. E por fim alguns traços da historiografia didática sobre as influências da cultura germânica na formação da gente catarinense.

Blumenau indubitavelmente ocupa o imaginário de milhares de brasileiros quando o assunto é colonização alemã nas terras do Sul do Brasil, muito em decorrência dos esforços políticos e econômicos empreendidos da década de 1980 com vistas à recuperação da região do Vale do Itajaí após uma 
enchente de proporções catastróficas. Como veremos, se São Pedro de Alcântara foi eleita para representar o passado, ficando circunscrita a ele nas narrativas didáticas, Blumenau busca no passado os contornos para sua afirmação no presente, eleita como guardiã dessa memória sobre a colonização alemã em Santa Catarina.

Sobre a vinda dos primeiros imigrantes alemães e a fundação de São Pedro de Alcântara, Lucas Boiteux escreveu, no início do século XX:19

\begin{abstract}
Em 1827, com 139 colonos do Sul da Alemanha, o barão de Antonina fundou o núcleo Rio Negro, hoje Mafra. Engajara o governo vários regimentos irlandeses e alemães. Em 1828, instigados por agentes argentinos, revoltaram-se alguns desses batalhões. Batidos os amotinados e fuzilados os cabeças, foram os corpos militares dissolvidos. Com muitos soldados alemães e mais 116 famílias tudescas (sic) fundou o governo a Colônia de São Pedro de Alcântara (BOITEUX, 1920, p. 100).
\end{abstract}

Depreende-se dessa narrativa que a vinda dos primeiros imigrantes alemães se deu por questões militares, e a fundação de São Pedro de Alcântara fora apenas uma consequência do desfecho menos feliz da empreitada. De fato, no livro A decadência de Santa Catarina, Oliveira e Salomon (2010) ressaltam que o aliciamento dos primeiros imigrantes alemães para as terras ao Sul do Brasil se aproximava muito mais dos objetivos do deslocamento de súditos, empreendido pela Coroa portuguesa no século XVIII, do que da política e dos negócios em torno da imigração iniciada no século XIX. O primeiro tinha como finalidade a ocupação estratégica para defesa do território português, já a segunda objetivava a colonização das terras para povoamento e aproveitamento econômico.

No mesmo livro, no capítulo cinco, chamado de Colonização Estrangeira, quando aborda a imigração empreendida de maneira mais efetiva a

19 Optamos por atualizar a grafia das palavras de acordo com as normas atuais da língua portuguesa. 
partir da década de 1840, há o seguinte destaque:

Em junho de 1840 assumia a presidência, em substituição ao general Andréa, o marechal Antero José Ferreira de Brito. Começou ele a tomar inúmeras medidas a fim de facilitar o desenvolvimento das províncias, assaz provada pela guerra civil. [...]

Em janeiro de 1850 era empossado no governo o dr. João José Coutinho, o administrador que por mais tempo dirigiu os destinos catarinenses. Sob sua esclarecida direção a província prosperou com muitos melhoramentos postos em prática. [...]

Nesse tempo foram fundadas as Colônias Blumenau, Joinville, D. Leopoldina, Militar e Belga, e criadas as freguesias do Sahym Paraty, Santo Amaro e Campos Novos (BOITEUX, 1920, p. 109-111).

$\mathrm{O}$ entrelaçamento entre aspectos políticos e militares perpassa toda a narrativa de Lucas Boiteux, que, com essa obra, didatizava uma versão de sua própria história sobre o Estado de Santa Catarina, publicada em 1912, intitulada Notas para a História catarinense ${ }^{20}$. Na leitura realizada por Boiteux importava dar destaque às mãos que conduziram os fatos como feitos, e apresentar um grande número destes. É nessa perspectiva que ele narra a vinda dos imigrantes como uma medida empreendida para facilitar o desenvolvimento das províncias, e segue apresentando de maneira breve a fundação dos núcleos coloniais nos diferentes governos. Assim, as colônias e os imigrantes que ali se estabeleceram não são compreendidos como sujeitos ativos no processo, mas apenas como objetos da ação política de outrem. Toda a particularidade da questão encontra-se subsumida na necessidade de cada governador em fazer o melhor para o desenvolvimento da província.

Décadas mais tarde, o sobrinho de Lucas Boiteux, Walter Piazza, em parceria com Laura Hübener (1987), vai elaborar uma narrativa didática para Santa Catarina, referenciada nas obras do tio, mas também fruto de seus trabalhos e pesquisas como historiador. Sobre a fundação de São Pedro de

${ }^{20}$ Sobre a historiografia catarinense e a escrita da história escolar de Lucas Alexandre Boiteux no início do século XX, ver: Silva; Cunha (2015). 


\section{Alcântara no livro Santa Catarina História da Gente lê-se:}

São Pedro de Alcântara, como núcleo populacional, surgiu dentro da política de integrar o litoral ao planalto, no sentido de dar apoio socioeconômico à região e servir de base a qualquer operação militar.

Em 1828, o Governo Central ordenava ao Presidente da Província de Santa Catarina que instalasse os colonos alemães recém-chegados, uns provenientes de Bremen e outros da chamada "Legião Alemã", corpo de tropa mercenária, dissolvida no Rio de Janeiro.

O local, para o estabelecimento da colônia, foi escolhido pelo Sargento mor Silvestre José dos Passos, nomeado diretor da Colônia São Pedro de Alcântara. A escolha recaiu no sertão acima da Vila de São José, às margens do rio Maruí.

Entretanto, o Governo da Província e Diretor da colônia enfrentam problemas como a discórdia entre os colonos com respeito à localização, $\mathrm{o}$ atraso de pagamento a que tinham direito durante o primeiro ano e principalmente à má distribuição de terras.

Aliados a esse problema, surgiram outros obstáculos ao desenvolvimento da Colônia, como a introdução nela, de ex-soldados que não eram agricultores, a impossibilidade de expansão agrícola em virtude do relevo acidentado e ainda a inadequação dos produtos tradicionalmente cultivados na Europa com o meio geográfico, de características tropicais.

Com isso, muitos colonos desertaram do local dirigindo-se para outras áreas da província.

Com a decretação da Lei Geral de 1830 [...] a colônia foi abandonada à própria sorte (PIAZZA; HÜBENER, 1987, p. 54-55).

Além de um texto com maior detalhamento, a fundação da Colônia de São Pedro de Alcântara é narrada aqui em um contexto que esclarece desde a origem dos alemães que nela foram instalados até as causas para seu insucesso. Sobre a origem, ressalta a preocupação em destacar que parte era composta de famílias vindas de Bremen e apenas outra parte de ex-soldados que compunham a Legião Alemã, possivelmente aqueles aos quais se referia Boiteux (1920). Além disso, a inserção desse grupo em meio aos colonos é apontada como uma das causas para o fracasso da colônia, já justificando de maneira prévia a importância que a seleção adequada dos imigrantes desempenhará um papel fundamental na 
colonização empreendida a partir de 1850.

Se a questão militar ainda está presente no texto, a questão política aparece mais para apontar erros estratégicos no estabelecimento dessa colônia do que para elevar os feitos deste ou daquele governante, além de colocar o presidente da província no lugar de obedecer às ordens do Governo Geral. Contudo, os imigrantes seguem não sendo reconhecidos como sujeitos nesse processo, apesar de a contextualização feita pelos autores já nos possibilitar ampliar as perspectivas sobre o tema.

Importante lembrar que essa é uma obra escrita para o $2^{0}$. Grau, denominação à época do atual Ensino Médio, o que implica também maior estabelecimento de relações entre as ocorrências históricas e maior complexidade da narrativa elaborada. O que não quer dizer que as narrativas históricas voltadas para o Ensino Fundamental, no caso da História Regional particularmente para o $4^{\circ}$ e $5^{\circ}$ anos, devam ser simplistas. Há aqui indiscutivelmente uma demanda pedagógica que atenta para a cognição e para o currículo prescrito para essa fase escolar, mas isso não significa que, dentro das expectativas estabelecidas, o conhecimento histórico não deva ser contextualizado e relacionado aos demais conhecimentos com os quais dialoga.

É com essas mesmas preocupações com as correlações, contextualização e estabelecimento de causa e efeito que Piazza e Hübener narram a fundação da Colônia Blumenau:

3.1 Colônia Blumenau

Com o objetivo de formar uma companhia colonizadora, Hermann Blumenau associou-se ao comerciante Fernando Hackradt e decidiram que a sede do estabelecimento comercial seria a região banhada pelo rio Itajaí-Açu. [...]

Os dezessete imigrantes que se estabeleceram naquela colônia possuíam as mais diversas profissões: havia agrimensor, carpinteiro, marceneiro, charuteiro, funileiro, ferreiro, dois lavradores. Deve-se ressaltar aqui a preocupação do Diretor da Colônia, Dr. Blumenau, quanto à seleção dos imigrantes. Não só no tocante às qualidades pessoais, mas principalmente quanto às aptidões, no sentido de haver 
uma diversificação profissional (PIAZZA; HÜBENER, p. 67, 1987).

Em meados do século XIX a imigração se tornou um negócio político, econômico e social com características particulares. Nas palavras de Oliveira e Salomon (2010, p. 93) "a constituição da imigração como um mecanismo de governo da população no Brasil é um movimento singular", em especial por vincular a posse da terra ao seu cultivo, como uma função pedagógica de formar o trabalhador produtivo e racional, absorvendo de forma satisfatória alemães. A articulação de detalhes sobre o grupo selecionado para a fundação da colônia do Dr. Hermann Blumenau nos dá mostras de uma narrativa didática que pode ser lida na perspectiva proposta por Oliveira e Salomon (2010). Se os imigrantes continuam no lugar de objetos de uma ação que sofrem, são agora um objeto detalhado, escolhido, com vistas ao melhor proveito do empreendimento. Um empreendimento cuja responsabilidade passa a ser agora de terceiros, interessados nos lucros entrevistos pelo negócio.

Pelo detalhamento da narrativa histórica de Piazza e Hübener, chama atenção o que encontramos no livro Os Catarinas - Terra e Gente (PIAZZA et al., 1994), voltado para os Estudos Sociais ministrada no 4ํ Ano. Todo o conteúdo que diz respeito à fundação das colônias alemãs em Santa Catarina no século XIX está resumido em uma página, ilustrada por um mapa com a localização desses imigrantes. Do texto destacamos os seguintes trechos:

A partir da sua independência o Brasil iniciou, de fato, uma política de colonização.

Assim, em 1824, foram localizadas em várias partes do território brasileiro famílias estrangeiras. Nessa ocasião foi fundada a Capela da Mata (atuais cidades do Rio Negro e Mafra) ao longo do "caminho-detropas".

Depois, em 1829, foi fundada a Colônia São Pedro de Alcântara, onde se localiza o atual município de São José.

Mais tarde, em 1850, gente de origem alemã, sob a direção do Dr. Hermann Blumenau, fundou a Colônia que levou o nome do fundador: Blumenau (PIAZZA et al., 1994, p. 52). 
Há elementos novos agrupados nesse subitem denominado "A colonização alemã", como a "Capela da Mata" e o "caminho de tropas", mas persiste o silenciamento sobre o papel de sujeito dos imigrantes somado à descontextualização do processo imigratório. Aliás, no decorrer desses quatro parágrafos, não há sujeitos para além do "Brasil" na condução desse empreendimento. É uma leitura factual, quase negligente, se admitirmos o conhecimento do autor sobre a questão. Por outro lado, podemos problematizar que à época a concepção de didatização do conhecimento correspondia muitas vezes à simplificação deste, particularmente quando as disciplinas de História e Geografia foram agrupadas sob a denominação de Estudos Sociais, conferindo à história das disciplinas escolares no Brasil um capítulo particular.

Contemporâneo a essa obra, portanto inserido no mesmo contexto político e pedagógico, temos o livro Santa Catarina - Estudos Sociais (QUEVEDO et al., 1994), no qual lemos:

\footnotetext{
Em 1822, o imperador D. Pedro I elaborou um projeto para colonizar as áreas incultas no interior do Brasil com imigrantes alemães, que viriam para desenvolver a agricultura. A primeira tentativa ocorreu em 1829, quando 166 famílias alemãs vindas da cidade de Bremen foram instaladas em São Pedro de Alcântara. Mais tarde essa colônia seria abandonada (QUEVEDO et al., 1994, p. 42).
}

"O que se conta" continua sendo a fundação de São Pedro de Alcântara e a vinda dos primeiros imigrantes, mas o como se conta já nos dá mostras de alterações nos sentidos da narrativa. Na escrita de Boiteux (1920), os governadores se sobressaem como sujeitos da ação de promover a imigração, em franca sintonia com as demandas políticas e sociais do início do século $\mathrm{XX}$, quando as oligarquias regionais ainda se esforçavam para manter seus privilégios e núcleos de poder. Já em Quevedo et al. (1994) o único sujeito nomeado no excerto anteriormente reproduzido é D. Pedro I, considerado responsável pela independência brasileira do jugo português (há controvérsias). De acordo com os autores, o imperador brasileiro elaborou um projeto com um objetivo bem 
delimitado: "colonizar áreas incultas no interior do Brasil". E para essa finalidade promoveu a vinda de famílias alemãs originárias de Bremen e com destino a São Pedro de Alcântara. As questões militares não são mais mencionadas, assim como as causas da falência do empreendimento. A narrativa, porém, ainda que de maneira resumida, contextualiza e elabora uma compreensão de sentido circular, ou ainda com início, meio e fim, além de sujeitos reais da ação.

Sobre a fundação de Blumenau, os autores escrevem:

Em 1847, chegou em nosso Estado o alemão Hermann Bruno Otto Blumenau, para visitar as colônias de São Pedro de Alcântara e Freguesia do Santíssimo Sacramento, hoje Itajaí.

O Dr. Blumenau reuniu novos colonos em 1850, a quem distribuiu lotes de terras nas margens do rio Itajaí-Açu. Dez anos depois, o governo brasileiro adquiriu a colônia e passou a denomina-la Colônia Blumenau, que foi elevada à condição de município em 1880 (QUEVEDO et al., 1994, p. 42-43, grifo no original).

Nessa narrativa o Dr. Hermann Bruno Otto Blumenau, com nome e todos os sobrenomes, é o principal sujeito das ações levadas a cabo para fundação da colônia no Vale do Itajaí. Foi ele o responsável pela aquisição dos lotes, seleção e distribuição dos colonos.

As narrativas acima transcritas têm em comum o fato de os imigrantes não serem considerados sujeitos das ações praticadas em nenhum momento. $\mathrm{O}$ lugar que eles ocupam é de objeto das ações de sujeitos que variam conforme as leituras empreendidas nas diferentes temporalidades. Ora os responsáveis são os presidentes das províncias de Santa Catarina, ora são submetidos ao Governo Geral; então aparece D. Pedro I como responsável pelo planejamento da imigração e por fim o protagonismo fica por conta dos novos financiadores do empreendimento, como o Dr. Blumenau.

Por outro lado, o quadro que traçamos sobre quem foram esses imigrantes vai se alterando e complexificando à medida que analisamos as 
diferentes narrativas, cada uma oferecendo elementos novos para composição do quadro. Acreditamos que esse é o potencial que a leitura dos livros didáticos como "textos de memória" ofereça ao ensino de História: a contraposição das narrativas didáticas elaboradas em temporalidades distintas e a consequente elaboração de uma leitura partilhada sobre o passado na relação ativa de ensino-aprendizagem, entre professores/as e estudantes em sala de aula.

\section{CONTRIBUIÇÃO DOS IMIGRANTES ALEMÃES PARA AS CULTURAS CATARINENSES}

Exceto na narrativa de Boiteux (1920), na qual não identificamos referência à contribuição dos imigrantes alemães para os traços culturais da gente catarinense, o tema é sem dúvida o que aparece com maior nível de detalhamento nos livros didáticos regionais. E nessa construção narrativa, como observamos a seguir, os imigrantes assumem outro lugar, qual seja, uma posição mais ativa como influenciador e formador de uma dada cultura catarinense.

Em Piazza e Hübener (1987), observamos a preocupação em destacar como os germânicos buscavam conciliar seus hábitos culturais e alimentares aos locais

Quanto aos alemães, a sua contribuição foi marcante através da introdução dos seus hábitos e costumes, embora para que pudessem se ajustar ao meio, tivessem que adotar uma serie de costumes locais.

[...] Ao lado de produtos já tradicionalmente cultivados na região, passavam a plantar aqueles nos quais recaíam sua preferência alimentar, como era o caso da batata e do centeio.

Da mesma forma, deram início à produção de carne defumada, linguiças e queijos dos mais variados tipos, cujo gosto incorporou-se ao do brasileiro em geral (PIAZZA; HÜBENER, 1987, p. 73).

No entanto, se pensarmos na vinda dos primeiros imigrantes no século 
XIX, devemos problematizar como esses costumes locais foram apropriados dada a subalternização que à época foram submetidos os habitantes originários das terras brasileiras. As terras destinadas à ocupação dos imigrantes eram consideradas pelo Governo Imperial e da Província como terras devolutas, ainda que muitas vezes já fossem habitadas e trabalhadas pelos indígenas, com os quais então estabelecia-se o confronto para tomada delas. A elaboração dessa leitura conciliatória se deu posteriormente, mais especificamente na década de 1930, quando da Campanha de Nacionalização do Ensino ${ }^{21}$ e adequação das particularidades regionais à imposição de um ideal de História da Nação que persiste até os dias atuais.

A narrativa de Piazza e Hübener (1987) também confere destaque para a arquitetura alemã e as atividades econômicas desenvolvidas por esses imigrantes, reforçando a vinculação dessa etnia com noções de prosperidade e modernização. Ressaltam os autores que:

Embora as primeiras construções fossem simples ranchos cobertas de sapé, à medida que melhorava a situação econômica, passavam a construir as casas típicas alemães (sic), tão conhecidas por nós: tijolos à vista, telhado em ângulo agudo, a existência do sótão, cortinas nas janelas, os inseparáveis jardins.

As suas atividades econômicas como a produção dos moinhos, das serrarias, dos curtumes, das fábricas de ferramentas, das cervejarias, dos laticínios, contribuíram para o desenvolvimento do mercado interno, já que esses produtos não eram voltados exclusivamente para o exterior, como até então, de uma maneira geral, caracterizou-se o comércio nacional. Estas atividades eram estimuladas pelas ideias "modernizadoras" que, de certa forma, haviam atingido os seus estados de origem, através da Revolução Industrial.

${ }^{21}$ Em Santa Catarina o projeto de nacionalização de ensino visava não apenas uniformizar o sistema de educação, mas principalmente conformá-lo à nacionalidade brasileira, por meio do ensino da história pátria, ideais de nação e a proibição de ensino em outras línguas que não a vernácula nas escolas. Essa foi uma preocupação desde a reforma da instrução pública, em 1911, no governo de Vidal Ramos. Contudo, a instalação do "Estado Novo" inauguraria uma dinâmica diferente na política educacional no Estado. O Decreto-Lei n. 88 de 31 de março de 1938, que objetivou regular o funcionamento dos estabelecimentos de ensino em Santa Catarina, marca o final do processo de nacionalização iniciado em 1911 e abre nova fase, dessa vez mais agressiva, atingindo principalmente as escolas isoladas das zonas coloniais, que ainda ensinavam na língua do imigrante, principalmente o alemão e o italiano (SILVA, 2014b). 
Não podemos esquecer também a introdução de suas crenças religiosas preconizadas pelo luteranismo (PIAZZA; HÜBENER, 1987, p. 75).

Mais uma vez nota-se como a narrativa de um mesmo autor, com diferentes parcerias, assume outras nuances quando se trata do livro de Estudos Sociais. Em Santa Catarina - Terra e Gente (1994), lemos

Os povos germânicos trouxeram sua contribuição à língua, não só em nome das localidades (Blumenau e outros) como a introdução de palavras do dia-a-dia (morgen-morgo - medida de superfície).

As suas festas tradicionais também foram aqui estabelecidas, como a "Festa do Tiro ao alvo", com seus desfiles e a premiação aos "Reis do Tiro", as festas da cerveja e o "kerbs" (festa da colheita).

Como agricultores, intensificaram o plantio de culturas como da batata e do repolho, constantes da sua culinária.

Aqueles que tinham artesanato em seus lugares de origem trouxeram importante contribuição à tecelagem, à mecânica e a outros setores da economia, formando a partir daí a base industrial de suas comunidades (PIAZZA et al., 1994, p. 57).

O destaque aqui recai sobre as influências cotidianas, como a língua e a alimentação, contudo sem deixar de ressaltar a contribuição econômica e as festividades. Na sequência, os autores evidenciam a necessidade de atender tanto as demandas do ensino de História e Geografia - colocadas à época para os Estudos Sociais - como questões do presente, pautadas pela Eco $92^{22}$, sobre a tomada de consciência e conservação ambiental. No mesmo tópico em que abordam a influência dos colonizadores alemães e a contribuição destes para o desenvolvimento agrícola e industrial de Santa Catarina, os autores destacam as consequências das referidas atividades no ecossistema da região (PIAZZA et al., 1985, p. 58).

\footnotetext{
${ }^{22}$ Em 1992 foi realizado no Rio de Janeiro um encontro entre chefes de Estado organizado pelas Nações Unidas, cuja preocupação central era discutir os cuidados com o meio ambiente ante o desenvolvimento econômico e social, e os problemas por ele desencadeados. O evento ficou conhecido como Eco 92.
} 
Outro ponto que ainda merece destaque é o item "Turismo" dessa mesma obra, no qual chama-se atenção mais uma vez para as diversas festas tradicionais dos imigrantes europeus, esclarecendo que "as tradições dos colonizadores de Santa Catarina originaram várias festas que se transformaram em grandes atrações turísticas" (PIAZZA et al., 1985, p. 81). Em seguida são apresentadas imagens em preto e branco das seguintes comemorações: Oktoberfest Blumenau; Schützenfest - Jaraguá do Sul; Marejada - Iatajaí; Imagem com título de diversas festas; Festa do Vinho - Urussanga; Festa Nacional do Pinhão; Festa das Flores - Joinville; Festa da Maça - São Joaquim; Festa Pomerana Pomerode; Pavilhão da Fenarreco - Brusque.

Observa-se que antes do item "Turismo" temos o item "Localidades Históricas", no qual não é feita nenhuma referência às cidades de origem alemã, dando indícios de uma organização narrativa cujo lugar da cultura imigrante é definido pelos benefícios que dela se pode extrair no presente, como os lucros advindos do turismo.

Por fim temos leitura de Quevedo et al. (1994), na qual podemos perceber a intencionalidade dos autores em incluir os imigrantes alemães como parte do grupo de "brancos" na divergente tríade inventada para explicar a composição étnico-cultural (populações indígenas, negras e brancas) dos brasileiros. É nessa perspectiva que eles destacam no texto sobre a "Cultura Catarinense":

Dos brancos colonizadores, destacamos os portugueses e, a partir do século XIX também os imigrantes, principalmente alemães e italianos. Eles determinaram nossa organização política, a língua, a religião predominante, os hábitos alimentares, nosso modo de vestir, usos e costumes, etc. (QUEVEDO et al., 1994, p. 45).

Essa inserção dos alemães em um grupo da tríade identitária nos parece estratégica para afirmar sua importância para a formação da gente catarinense, mas sem considerá-los um "elemento estrangeiro", resistindo à marca que lhes fora atribuída na década de 1930. No intuito de valorizar esse lugar do imigrante 
alemão para a formação histórica, cultural e econômica catarinense, os autores destacam:

Esse povo contribuiu para o progresso industrial em Santa Catarina, graças ao conhecimento que trouxe de seu país. É bem verdade que, inicialmente, se dedicaram à agricultura e ao artesanato, mas, com o capital adquirido na comercialização desses produtos, acabaram por dar início às primeiras indústrias (QUEVEDO et al., 1994, p. 43).

E, acompanhando as tendências observadas na narrativa de Piazza et al. (1994), também as festas de origem alemã são tema de destaque, dessa vez no item "Nossas tradições":

Mas se sairmos do litoral e formos para o nordeste do Estado, veremos as marcas de duas culturas europeias: a alemã e a italiana.

As festas trazidas pelos alemães soam conhecidas nacionalmente. Entre elas, podemos citar a festa do Rei do Tiro, que é uma disputa de tiro ao alvo. Festejemos com eles cantando

Trink, trink Brüderlein, trink; lass doch die Sorge zu Haus

(Beba, beba, irmãozinho, beba; deixe as preocupações em casa)

Agora, se não estiverem cansados, vamos para Blumenau, participar da Oktoberfest. Apesar de só haver começado em 1983, para alegrar o povo depois de um período de enchentes que praticamente destruíram o vale do Itajaí, ela já é considerada a segunda em importância no país, superada apenas pelo carnaval (PIAZZA et al., 1994, p. 48, grifo no original).

Mesmo em suas diferenças, observamos que no decorrer do século XX o traçado narrativo sobre a contribuição dos imigrantes alemães para a formação da gente catarinense constrói e reforça um lugar por meio da pedagogia do trabalho (OLIVEIRA; SALOMON, 2010), muito bem articulado pelo governo do Império ao arquitetar a vinda dos imigrantes de diferentes etnias para o Brasil. Nessa perspectiva, o alemão incorporou de maneira tão satisfatória a ideia que, em torno dele, criou-se a figura do trabalhador exemplar, cujos feitos 
contribuíram para o desenvolvimento agrícola e industrial do Estado catarinense, e cuja cultura contribui ainda hoje para fomentar o turismo na região. Como vimos no exercício de análise proposto, esse modelo de interpretação vai se afirmando no decorrer das décadas do século XX, silenciando tensões nas narrativas didáticas e reforçando os traços que contribuam para essa compreensão.

\section{CONSIDERAÇÕES FINAIS}

A imigração alemã, assim como de outras etnias que vieram para o Brasil, atenderam a objetivos particulares e distintos dos que incentivaram a vinda dos portugueses das ilhas dos Açores. Dentre eles, o desejo velado da elite intelectual e política no "embranquecimento" do povo que se formava nas terras brasileiras (SEYFERTH, 2002). E essa imigração deu origem a um capítulo particular na história do Estado de Santa Catarina, diferenciando o processo de formação histórica de sua gente, da narrativa modelo construída para o Brasil. Esse capítulo foi narrado em diferentes intensidades e tonalidades no decorrer do século $\mathrm{XX}$, dada as particularidades da cultura germânica e as interferências desencadeadas pela Alemanha na história mundial. As duas grandes guerras, aliadas ao desejo de se construir uma história brasileira sob os pilares de três povos - os portugueses, os indígenas e os africanos - acabaram, em um primeiro momento, por encobrir e silenciar a influência alemã na formação de Santa Catarina. E em um segundo momento, essa influência, reconhecida e elevada, acaba por suprimir ela mesma a consideração de outras etnias na formação do povo catarinense.

É nessa chave de compreensão que percebemos a partir da década de 1990, nos livros didáticos aqui analisados, um esforço do reconhecimento dos imigrantes alemães e de sua influência na cultura catarinense. Há aqui a tendência de se ressaltar aspectos referentes ao crescimento econômico e ao turismo - vinculado a cidades e festas, estabelecendo um laço entre a ideia de progresso econômico e a identidade germânica em Santa Catarina. Já costumes e 
influência culturais como a religião e a língua, por exemplo, são abordadas com certo zelo porque, de certo modo, confrontam a brasilidade catarinense representada pelos açorianos e todo o fardo português que carregavam consigo.

Por fim, mas não menos importante, investigar e explorar o livro didático como "texto de memória" dialoga com uma proposta já feita por Alain Choppin (2004) no artigo História dos livros e das edições didáticas: sobre o estado da arte. Nele, o autor define quatro funções da obra didática: referencial, instrumental, ideológica-cultural e documental. Sobre esta última esclarece: "acredita-se que o livro didático pode fornecer, sem que sua leitura seja dirigida, um conjunto de documentos, textuais ou icônicos, cuja observação ou confrontação podem vir a desenvolver o espirito crítico do aluno" (CHOPPIN, 2004, p. 553). Ler o livro didático como um "texto de memória" possibilita essa confrontação entre narrativas de diferentes temporalidades e espaços, potencializando sua função documental e reconhecendo a polifonia que perpassa sua natureza hibrida. No caso do exercício aqui empreendido, apostamos que apresentar narrativas de diferentes temporalidades sobre a vinda dos imigrantes alemães para Santa Catarina e as influências culturais a eles relacionadas possa contribuir para evidenciar questões que cada presente coloca a seu passado, assim como as lentes de leituras autorizadas para elaboração de respostas. Talvez seja mais um caminho, entre outros possíveis, para ensinar e aprender História com a criticidade necessária, ampliando olhares sobre as diferentes narrativas em disputa. Esperamos que o olhar proposto sobre a narrativa didática, contrapondo narrativas históricas de diferentes temporalidades e, quando pertinente, de diferentes espaços, possa ser expandido por professores e pesquisadores em suas pesquisas e em salas de aula. E possa ser mobilizado, ainda, na compreensão dos traçados narrativos estruturantes da historiografia didática em diferentes escalas. ${ }^{23}$

\footnotetext{
${ }^{23}$ Agradecemos ao Prof. Dr. Luciano Roza (Universidade Federal de Ouro Preto - Ufop) pelos
} profícuos diálogos que contribuíram para o amadurecimento das reflexões aqui apresentadas. 


\section{REFERÊNCIAS}

BECHLER, Rosiane da Silva Ribeiro. Entre traçar histórias e tecer identidades: narrativas da historiografia didática regional sobre Santa Catarina. 2018. Tese (Doutorado em Educação) - Universidade do Estado de Santa Catarina/Udesc, Florianópolis/SC, 2018.

BECHLER, Rosiane da Silva Ribeiro. Minas Gerais em escalas: variações do conhecimento histórico escolar em livros didáticos regionais. 2014. Dissertação (Mestrado em Educação) - Universidade Federal de Minas Gerais/UFMG, Belo Horizonte/MG, 2014.

BOITEUX, Lucas Alexandre. Notas para a história catarinense. Florianópolis: Tip. a vapor da Livraria Moderna, 1912.

BOITEUX, Lucas Alexandre. Pequena história catarinense. Ilustrada. Florianópolis: Oficinas a Eletricidade da Imprensa Oficial, 1920.

CHOPPIN, Alain. História dos livros e das edições didáticas: sobre o estado da arte. Educação e Pesquisa: Revista de educação da USP, São Paulo, v. 30, p. 549-566, set./dez. 2004.

CHRISTOPHE, Barbara. Ambivalenz als Ressource? Litauische Geschichtslehrer als Übersetzer von kulturellen Deutungsmustern des Sozialismus. In: NIKZENTAITIS, Alvydas (Hg.). Die Vielschichtigkeit der Erinnerung. Stadt, Staat, Region. Vilnius: Atminties daugiasluoksniskumas, 2013. (Ambivalência como pesquisa? Ensino de História lituânia como tradução de modelos de interpretação cultural do Socialismo).

CHRISTOPHE, Barbara; SCHWEDES, Kerstin (ed.). Schulbuch und Erster Weltkrieg: Kulturwissenschaftliche Analysen und geschichtsdidaktische Überlegungen. Göttingen: V\&R unipress GmbH, 2015.

CUESTA FERNANDEZ, Raimundo. El código disciplinar de la historia escolar en España: algunas ideas para la explicación de la sociogénesis de una materia de enseñanza. Encounters on Education, v. 3, p. 27-41, 2002. Disponível em: http://qspace.library.queensu.ca/handle/1974/458. Acesso em: $11 \mathrm{dez}$. 2016.

HALBWACHS, Maurice. A memória coletiva. Tradução Laís Teles Benoir. São Paulo: Centauro, 2004.

KNOCH, Habbo. Die Tat als Bild: fotografien des Holocaust in der deutschen Erinnerungskultur. Hamburg: Hamburger Edition, 2001. 
MUNAKATA, Kazumi. O livro didático: alguns temas de pesquisa. Revista Brasileira de História da Educação, v. 12, n. 3 [30], p. 179-197, 2013. Disponível em: http://www.rbhe.sbhe.org.br/index.php/rbhe/article/view/455. Acesso em: 3 set. 2015.

OLIVEIRA, Henrique; SALOMON, Marlon. A decadência de Santa Catarina. Florianópolis: Ed. da UFSC, 2010.

PIAZZA, Walter Fernando; HÜBUNER, Laura Machado. Santa Catarina história da gente. Florianópolis: Editora Lunardelli, 1987.

PIAZZA, Walter Fernando; LOMBARDI, Ivete; LEITE, Mara de Fátima. Os Catarinas - terra e gente. Florianópolis: Editora Lunardelli, 1994.

QUEVEDO, Julio; SALES, Geraldo Francisco de; ORDOÑES, Marlene. Santa Catarina, Estudos Sociais. Coleção Meu Estado. São Paulo: Scipione, 1994.

RICOEUR, Paul. A memória, a história, o esquecimento. Campinas: Editora da Unicamp, 2007.

SEYFERTH, Giralda. Colonização, imigração e a questão racial no Brasil.

Revista USP, n. 53, p. 117-149, 2002. Disponível em:

https://scholar.google.com.br/scholar?hl=pt-

BR\&as_sdt=0\%2C $5 \& \mathrm{q}=$ Coloniza\% $33 \% \mathrm{~A} 7 \% \mathrm{C}_{3} \% \mathrm{~A} 30 \% 2 \mathrm{C}+$ imigra\% $\mathrm{C}_{3} \% \mathrm{~A}_{7} \% \mathrm{C}_{3}$ $\%$ A30+e+a+quest\%C3\%A30+racial+no+Brasil\&btnG. Acesso em: 14 abr. 2017.

SILVA, Cristiani Bereta. Educar para a nação: cultura política, nacionalização e ensino de história nas décadas de 1930 e 1940. Curitiba: CRV, 2014b.

SILVA, Cristiani Bereta. Nação e região e a unidade nacional: uma leitura a partir de dois livros didáticos de História publicados na Primeira República. Revista Brasileira de Educação, Rio de Janeiro, v. 19, n. 57, p. 349-374, abr./jun. 2014a. Disponível em: http://www.scielo.br/pdf/rbedu/v19n57/v19n57a05.pdf. Acesso em: 31 jul. 2014.

SILVA, Cristiani Bereta; CUNHA, Maria Teresa Santos. Historiografia catarinense e a escrita da história escolar de Lucas Alexandre Boiteux no início do século XX. Cadernos de História da Educação, v. 14, 2015, p. 551-568. Disponível em:

http://www.seer.ufu.br/index.php/che/article/view/32524/17509. Acesso em: fev. 2018. 
ROSIANE RIBEIRO BECHLER é doutora em Educação pela Universidade do Estado de Santa Catarina (Udesc), sob orientação da Profa. Dra. Cristiani Bereta da Silva, vinculada à linha de História e Historiografia da Educação. Investiga a elaboração da narrativa histórica dos livros didáticos regionais, com ênfase na discussão da relação entre regionalidades, etnicidades e identidade nacional. É pesquisadora colaboradora do Instituto Internacional de Pesquisas sobre Livros Didáticos Georg-Eckert/Alemanha e faz parte do Grupo de Pesquisa Ensino de História, Memória e Culturas (CNPq/Udesc) e do Laboratório de Ensino de História da Udesc. Trabalhou como professora substituta na Universidade Federal de Santa Catarina (UFSC) (2015-2016), ministrando as disciplinas de Estágio Supervisionado em História I, II e III. Possui Mestrado em Educação (2014) pela Faculdade de Educação da Universidade Federal de Minas Gerais (UFMG) e é graduada em História (2006) pela Faculdade de Filosofia e Ciências Humanas da mesma Universidade. Desde 2005 atua como colaboradora/pesquisadora do Laboratório de Estudos e Pesquisas em Ensino de História da Faculdade de Educação da UFMG. Nesse período, atuou como apoio técnicopedagógico junto à coordenação do Curso de Aperfeiçoamento Produção de Materiais Didáticos para a Diversidade (Labepeh/UFMG - 2010) e à coordenação do Programa Nacional da Biblioteca na Escola (PNBE) Temático 2013. Atuou na docência como professora voluntária da Escola Leo-Deeg, na cidade de Wüzburg, Alemanha entre 2007-2009; e também no Centro Pedagógico da UFMG em Belo Horizonte (2011), com alunos entre 9-13 anos. Tem experiência na área de História, com ênfase em Ensino de História, principalmente nos seguintes temas: ensino de história local/regional, currículo e livros didáticos.

E-mail: rosiribeirobechler@gmail.com

(D) http://orcid.org/0000-0001-7551-5533

CRISTIANI BERETA DA SILVA é graduada em História pela Universidade Federal de Santa Catarina (UFSC) (1998) com doutorado em História pela mesma Universidade (2003). Realizou estágio pós-doutoral na Universidade Estadual de Campinas (Unicamp), em 2011 e na Universidad de Alcalá (UAH) (Espanha), em 2015. Professora titular do Departamento de História, atuando também como professora permanente no Programa de Pós-Graduação em História e no Mestrado Profissional em Ensino de História (ProfHistória) e, como professora colaboradora, no Programa de Pós-Graduação em Educação, todos na Universidade do Estado de Santa Catarina (Udesc). Pesquisadora do Grupo de Pesquisa Ensino de História, memória e culturas (CNPq/Udesc), vinculado ao Laboratório de Ensino de História (LEH/Udesc) e do Grupo de Pesquisa Oficinas de História (CNPq/Uerj). Associada da Associação Nacional de História (Anpuh), da Sociedade Brasileira de História da Educação (SBHE) e da Associação Brasileira de Ensino da História (Abeh). Desenvolve pesquisas na área de História e Ensino de História com ênfase em História e interfaces com a Educação, privilegiando os seguintes temas: ensino de história, historiografia, história regional, história do Brasil, mobilizando categorias/conceitos relativos a cultura política, cultura histórica, narrativas 
e memórias, no âmbito da História do Tempo Presente. Foi editora da Revista História Hoje - ANPUH-Brasil (Biênio 2015-2017). Coordenou o Programa de Pós-Graduação em História da Udesc entre 2015 e maio de 2018. Atualmente é coordenadora de área da Capes dos Programas Profissionais em História. Bolsista Produtividade em Pesquisa do CNPq.

E-mail: cristianibereta@gmail.com

(iD) http://orcid.org/0000-0003-2304-0307

Recebido em: 30 de março de 2018

Aprovado em: 05 de janeiro de 2019 